\title{
Fundal Height as a Predictor of Early Preterm Triplet Delivery
}

\author{
Yoshie Yokoyama \\ College of Medical Technology, Kyoto University
}

\begin{abstract}
The purpose of this study was to create graphs of fundal height parameters in triplet pregnancies compared with those in twin pregnancies, and to investigate whether larger fundal heights in triplet pregnancies would predispose them to earlier delivery (before 34 weeks). The subjects were 727 twin pregnant women and 133 triplet pregnant women, who delivered after 1984. Triplet pregnancies showed significantly higher fundal heights compared with twin pregnancies at each gestational age (weeks). In triplet pregnancies, a single fundal height measurement above the 90th percentile before 34 weeks yielded a sensitivity of $31.3 \%$ and specificity of $82.4 \%$ for delivery before 34 weeks, with a positive predictive value of $50.0 \%$ and a negative predictive value of $68.0 \%$. After adjusting for each associated factor using logistic regression, the risk of preterm labour was not significantly associated with a single fundal height measurement above the 90th percentile recorded before 34 weeks.
\end{abstract}

Multiple births have risen in recent decades (Botting et al., 1987; Imaizumi, 1992; Imaizumi, 1994; Kiely et al., 1992; Levene et al., 1992). In particular, the birth rate for triplets has dramatically increased from 58 per million births in 1951 to 275 in 1994 in Japan (Imaizumi, 1994). Twin pregnancies have greater fundal heights (Leroy et al., 1982) and larger intrauterine volumes (Redford, 1982) than singleton pregnancies. Comparable figures for triplet pregnancies are few, but fundal heights for triplet pregnancies are probably greater. In addition, uterine overdistention is commonly indicated to predispose early delivery (Quilligan, 1981). The purpose of this study was to create graphs of fundal height parameters during triplet pregnancies compared with those during twin pregnancies, and to investigate whether larger fundal heights in triplet pregnancies would predispose them to earlier delivery (before 34 weeks).

\section{Subject and Method}

The subjects were 727 twin pregnant women and 133 triplet pregnant women, who delivered after 1984 . They were recruited from the Kyoto University Twin and Higher Order Multiple Birth Registry. The participants in this study were collected from several sources, such as mothers who responded to newspaper advertisements and magazine articles featuring nursing guidance for families with multiple births, the Japanese Mother's Organization for Twin and Higher Order Multiple Births and referrals from midwives and public health nurses. For these pregnancies, data on fundal height, infertility treatment, maternal height, preterm rupture of membrane, polyhydramnios, birthweight and gestational age were obtained from records in Maternal and Child Health Handbooks. This handbook was established by the Maternal and Child Health Law in Japan and is provided by the governor after a report of pregnancy. The purpose of this handbook is the maintenance of maternal and child health: medical examinations during pregnancy, the condition of the newborn, the progress of infant growth, periodic medical examinations for the infant, and preventive injections are recorded. Further, it is established by the Maternal and Child Health Law that all pregnant women receive medical examinations during pregnancies. Pregnant women are examined by obstetricians, and their fundal heights are routinely measured in all cases using a flexible nondistensible tape from the superior border of the symphysis pubis to the upper extent of the uterine fundus, as determined by gentle indentation of the abdominal wall.

Chi-square analysis was performed to examine ratios. Statistical analysis of fundal heights was a one-way analysis of variance with repeated measures. Sensitivity, specificity, and positive and negative predictive values for delivery before 34 weeks were calculated for a single fundal height measurement above the 90th percentile recorded before 34 weeks. Further, logistic regression was used to adjust for fundal height measurement and other factors associated with early preterm delivery (before 34 weeks). Data were analysed using the SPSS statistical package.

\section{Results}

Table 1 summarises the characteristics of twin and triplet pregnancies in this study. Triplet pregnancy following infertility treatment is significantly higher than twin pregnancy. The odds ratio indicated that triplet pregnancies were 9.67 times more likely to follow infertility treatment than twin pregnancies. Mean birthweight in triplets was significantly lower than that in twins, and the rate of babies weighting under $1500 \mathrm{~g}$ in the set was significantly associated with the number of children in multiple pregnancies. The odds ratio indicated that triplet pregnancies were 8.00 times more likely to have babies weighted under $1500 \mathrm{~g}$ in the set than twin pregnancies. There was a significant difference in delivery before 34 weeks' gestation between triplet pregnancies

Addres for correspondence: Yoshie Yokoyama, College of Medical Technology, Kyoto University, 53 Kawahara-cho, Shogoin, Sakyo-ku, Kyoto 606-8507, Japan.Email: yokoyama@itan.kyoto-u.ac.jp 
Table 1

Major Characteristics of Subjects for Twin and Triplet Pregnancies

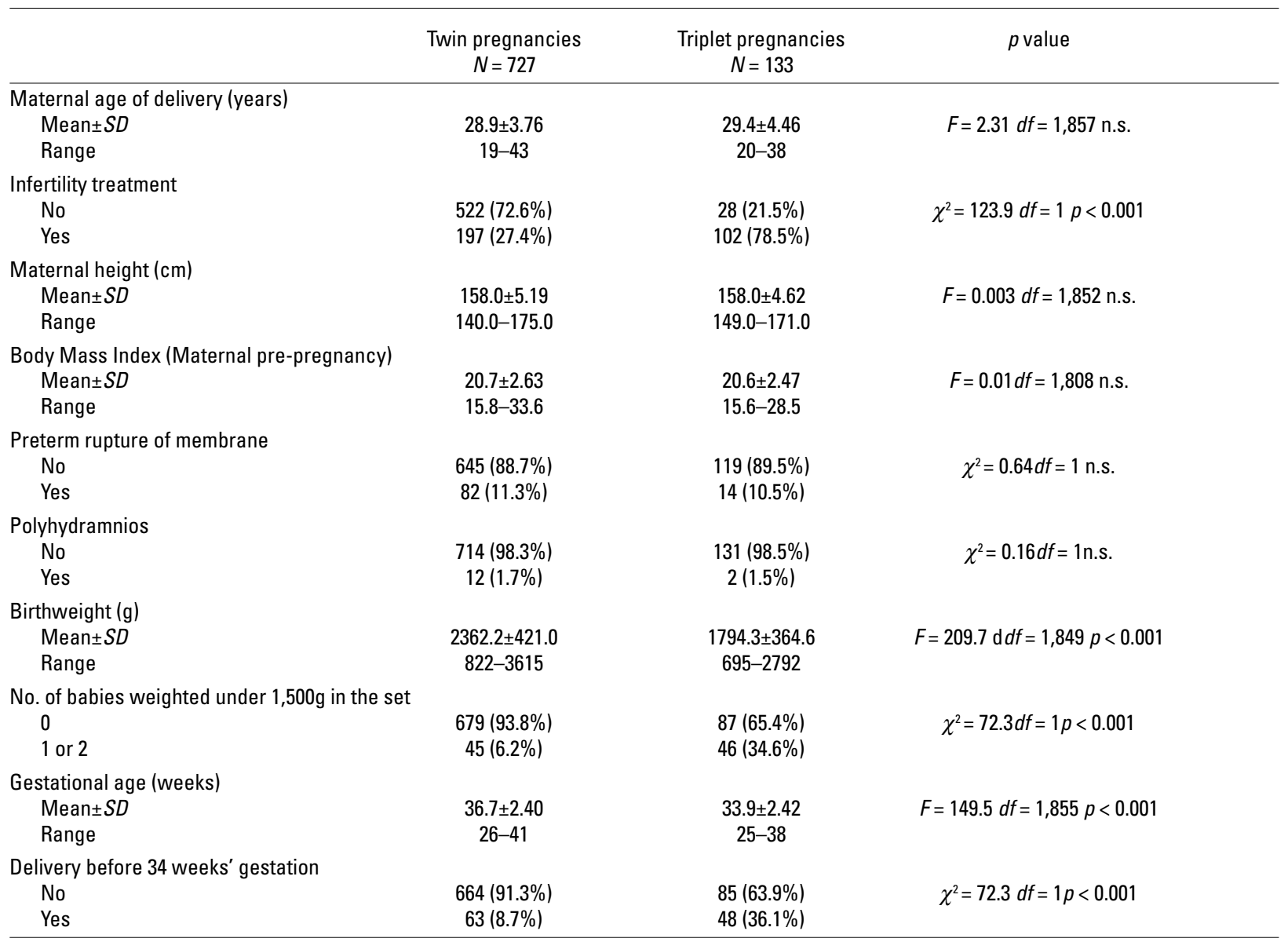

and twin pregnancies: $36.1 \%$ of triplet pregnancies delivered before 34 weeks' gestation, while $8.7 \%$ of twin pregnancies delivered before 34 weeks' gestation.

Figure 1 shows fundal height curves during triplet pregnancies compared with those during twin pregnancies. Triplet pregnancies showed significantly higher fundal heights compared with twin pregnancies at each gestational age (weeks).

Figure 2 portrays the mean, tenth and 90th percentile fundal heights for triplet pregnancies in 133 gravida. Figure 3 shows selected fundal heights in triplet pregnancies with exclusions for preterm rupture of membranes or polyhydramnios. Figure 4 illustrates the fundal heights in two groups of triplet pregnancies that were categorised as $\geq 34$ weeks or $<34$ weeks on gestational age at delivery.

As shown in Table 2, in triplet pregnancies, a single fundal height measurement above the 90 th percentile before 34 weeks yielded a sensitivity of $31.3 \%$ (15 of 48) and specificity of $82.4 \%$ (70 of 85 ) for delivery before 34 weeks, with a positive predictive value of $50.0 \%$ (15 of 30) and a negative predictive value of $68.0 \%$ (70 of 103).

Table 3 shows the results of logistic regression on early preterm delivery (before 34 weeks) with associated factors as independent variables. A single fundal height above 90th percentile was not associated with the incidence of early preterm delivery in triplet pregnancy. Preterm rupture of membrane was associated with the incidence of early preterm delivery: The odds ratio indicated that pregnant women who had preterm rupture of membranes were 7

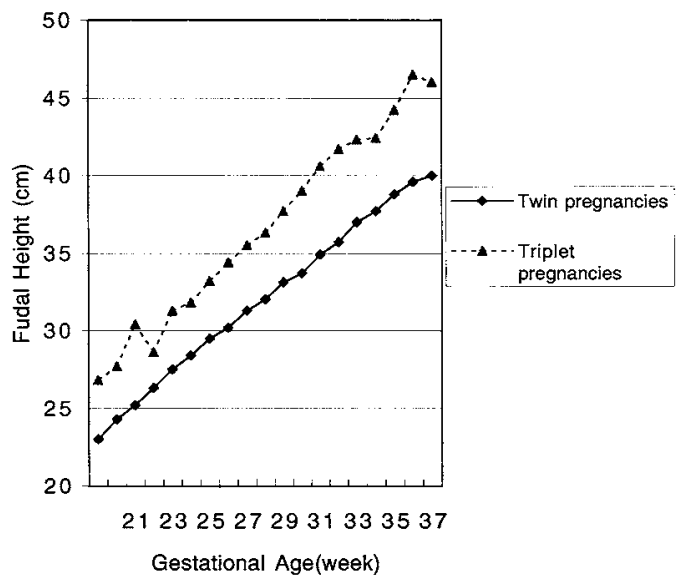

Figure 1

Fundal heights in twin and triplet pregnancies* $p<0.001$ at each gestational age. 


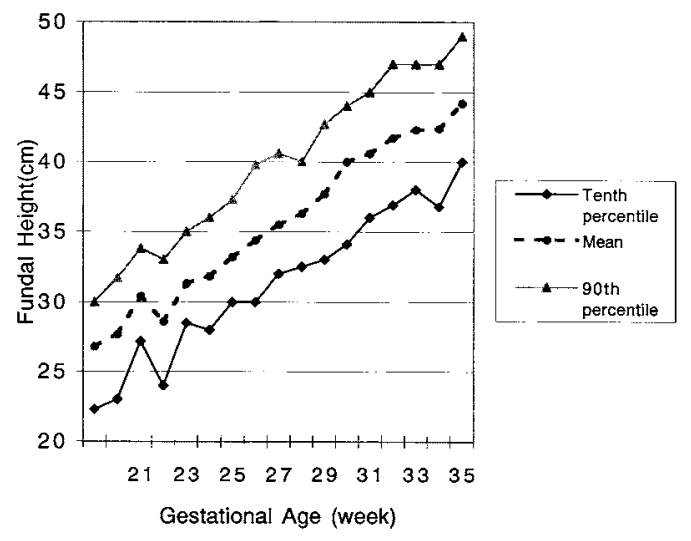

Figure 2

Fudal heights by gestational age of triplet pregnancies.

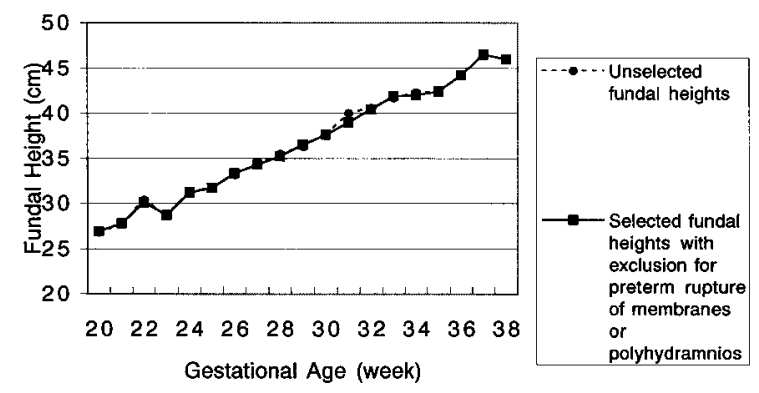

\section{Figure 3}

Unselected fundal heights and selected fundal heights with exclusions for preterm rupture of membranes or polyhydramnios.

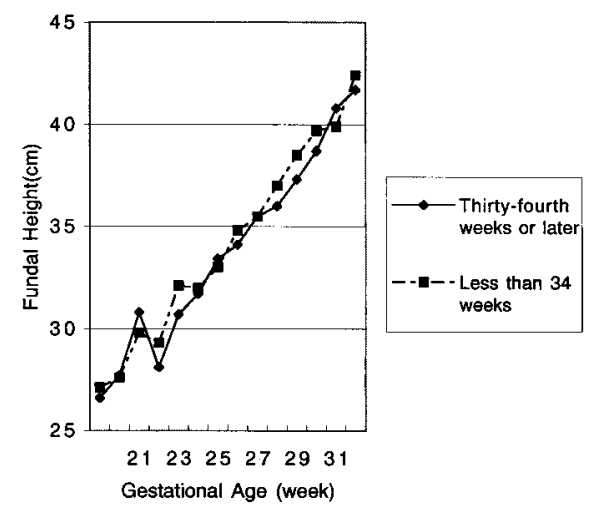

Figure 4

Fundal heights by gestational age at delivery in two groups of triplet pregnancies which were categorized on gestational age at delivery.

times more likely to deliver before 34 weeks' gestation than those who did not have preterm rupture of membranes.

\section{Discussion}

There is a sampling bias in this study because the data are not based on population data of triplet deliveries in Japan. However, because of Japanese privacy protection laws, it
Table 2

Relationship of Fundal Height to Early Preterm Triplet Delivery

\begin{tabular}{ccc}
\hline Delivery & $\begin{array}{l}\text { Single } \\
\text { above } \text { 90th percentile }\end{array}$ & $\begin{array}{c}\text { No fundal height } \\
\text { above 90th percentile }\end{array}$
\end{tabular}

\begin{tabular}{lcccc} 
& $n$ & $(\%)$ & $n$ & $(\%)$ \\
\hline$<34$ weeks & 15 & $(50.0)$ & 33 & $(32.0)$ \\
$\geq 34$ weeks & 15 & $(50.0)$ & 70 & $(68.0)$ \\
\hline Percentages
\end{tabular}

Percentages are column percentages.

* At least one fundal height measurement above the 90th percentile from 20-33 weeks.

\section{Table 3}

Results of Logistic Regression on Early Preterm Delivery (Before 34 Weeks) and Associated Factors in Triplet Pregnancy

\begin{tabular}{|c|c|c|}
\hline Independent variables & Odds ratio & $95 \%$ confidence interval \\
\hline \multicolumn{3}{|l|}{$\begin{array}{l}\text { Single fundal height } \\
\text { above 90th percentile }\end{array}$} \\
\hline No & 1.00 & \\
\hline Yes & $2.50^{+}$ & $0.91-6.92$ \\
\hline \multicolumn{3}{|c|}{ Preterm rupture of membrane } \\
\hline No & 1.00 & \\
\hline Yes & $7.02 *$ & $1.26-39.2$ \\
\hline \multicolumn{3}{|l|}{ Polyhydramnios } \\
\hline No & 1.00 & \\
\hline Yes & 1.14 & $0.06-23.2$ \\
\hline \multicolumn{3}{|l|}{ Infertility treatment } \\
\hline No & 1.00 & \\
\hline Yes & 1.01 & $0.34-2.96$ \\
\hline \multicolumn{3}{|l|}{$\begin{array}{l}\text { No. of babies weighted } \\
\text { under } 1,500 \mathrm{~g} \text { in the set }\end{array}$} \\
\hline 0 & 1.00 & \\
\hline 1 or 2 & $4.74 * * *$ & $1.89-11.9$ \\
\hline \multicolumn{3}{|l|}{ Body Mass Index (BMI) } \\
\hline$\geq 19.8$ & 1.00 & \\
\hline$<19.8$ & 2.13 & $0.86-5.30$ \\
\hline
\end{tabular}

was difficult to ascertain fundal heights by checking Japan's birth registries, and there has been no prior study on fundal heights in triplet pregnancies in Japan. A large number of subjects in this study were collected through advertisements in newspapers, periodicals and multiple birth clubs. However, since public services for families with multiple births are not widely available in Japan, mothers who are concerned about information of multiple births and childcare issues form the large majority. These mothers offered considerable data and co-operated with this study.

The fundal height measurements of twin pregnancies reported here are similar to those reported by Dwight et al. (1993). Accordingly, it was considered that the sampling bias in this study was not large.

Multiple births are associated with an increased risk of preterm delivery (Imaizumi \& Nonaka, 1998; Quilligan, 1981; Spellacy et al., 1990) Mean gestational age at delivery is 36.8 weeks and 34.2 weeks in twin and triplet pregnancies, respectively (Yokoyama et al., 1995). Why multiple pregnancies so frequently deliver prematurely is not known. The increased incidence of preterm labor is 
generally attributed to uterine overdistention (Quilligan, 1981). Moreover, it is reported that the correlation between intrauterine volume and fundal height measurement was highly significant (Gierroson \& Agustsson, 1987).

Several studies reported that there was no evidence that the measured fundal height is greater in twin pregnancies going on to preterm delivery (Dwight et al., 1993; Neilson et al., 1988). There have been few studies on fundal heights in triplet pregnancies due to the rarity of such births. This study did not indicate a tendency for triplet pregnant women who showed a single fundal height measurement above the 90th percentile recorded before 34 weeks to deliver preterm (before 34 weeks' gestation). However, since the population of triplet pregnancies is small in this study, the subjects should be increased and be reappraised in future.

Csapo et al. (1963) reported that acute increases in intrauterine volume induced uterine activity. Fundal heights in triplet pregnancies were substantially greater at each gestational age (weeks) than those in twin pregnancies, and greater acute changes in intrauterine volume in triplet pregnancies may be attributed to early preterm labour. However, it was difficult to obtain the measurements made with ultrasound in this study since they are not recorded in the Maternal and Child Health Handbook. These factors are important for comprehending early preterm labour in triplet pregnancies and thus should be investigated in the future.

\section{References}

Imaizumi, Y. (1994). Recent and long term trends of multiple birth rates and influencing factors in Japan. Journal of Epidemiology, 4, 103-109.

Botting, B. J., Davies, I. M., \& Macfarlance, A. J. (1987). Recent trends in the incidence of multiple births and associated mortality. Archives of Disease in Childhood, 62, 941-950.

Levene, M. J., Wild, J., \& Steer, P. (1992). Higher multiple births and the modern management of infertility in Britain. British Journal of Obstetrics and Gynaecology, 99, 607-613.
Kiely, J. L., Kleinman, J. C., \& Kiely, M. (1992). Triplets and higher-order multiple births: Time trends and infant mortality. American Journal of Diseases in Children, 146, 862-868.

Imaizumi, Y. (1992). Twinning rates in Japan. Acta Geneticae Medicae et Gemellologiae, 41, 165-175.

Leroy, B., Lefort, F., \& Jeny, R. (1982). Uterine height and umbilical permeter curves in twin pregnancies. Acta Geneticae Medicae et Gemellologiae, 31, 195-198.

Redford, D. (1982). Uterine growth in twin pregnancy by measurement of total interauterine volume. Acta Geneticae Medicae et Gemellologiae, 31, 45-48.

Quilligan, E. (1981). Pathologic casuses of preterm labor. In M. Elder \& C. Hendricks (Eds.), Preterm labor (p.61). London: Butterworth.

Spellacy, W. N., Handler, A., \& Ferre, C. (1990). A case-control study of 1253 twin pregnancies from a 1982-1987 perinatal database. Obstetrics and Gynecology, 75, 168-171.

Imaizumi, Y., \& Nonaka, K. (1998). Yearly changes in stillbirth rates of zygotic twins in Japan, 1975-1994. Acta Geneticae Medicae et Gemellologiae, 47, 19-30.

Yokoyama, Y., Shimizu, T., \& Hayakawa, K. (1995). Prevalence of cerebral palsy in twins,

triplets and quadruplets. International Journal of Epidemiology, 24, 943-948.

Gierroson, R. T., \& Agustsson, F. (1987). Total intrauterine volume and symphysis fundal height. Acta Obstetricia Gynecologica Scandinavica, 66, 345-348.

Neilson, J., Verkuyl, D., \& Bannerman, C. (1988). Tape measurement of symphysis-fundal height in twin pregnancies. British Journal of Obstetrics and Gynaecology, 95, 1054-1059.

Dwight, J. R., Gregory, S. S., \& Frank, J. Z. (1993). Fundal height as a predictor of preterm twin delivery. Obstetrics and Gynecology, 81, 211-214.

Csapo, A. I., Jaffrin, H., Kerenyi, T., Lipman, J. I., \& Wood, C. (1963). Volume and activity of the pregnant human uterus. American Journal of Obstetrics and Gynecology, 85, 819-834. 